Canadian

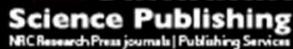

Canadian Geotechnical Journal Revue canadienne de géotechnique

\title{
Fragility curves for rainfall-induced shallow landslides on transport networks
}

\begin{tabular}{|c|c|}
\hline Journal: & Canadian Geotechnical Journal \\
\hline Manuscript ID & cgj-2016-0565.R2 \\
\hline Manuscript Type: & Article \\
\hline Date Submitted by the Author: & 09-Sep-2017 \\
\hline Complete List of Authors: & $\begin{array}{l}\text { Martinović, Karlo; Gavin \& Doherty Geosolutions, ; University College } \\
\text { Dublin, } \\
\text { Reale, Cormac; Delft University of Technology, Faculty of Civil Engineering } \\
\text { and Geosciences GeoEngineering Section; Gavin \& Doherty Geosolutions } \\
\text { Gavin, Kenneth; Delft University of Technology, Faculty of Civil Engineering } \\
\text { and Geosciences; Gavin \& Doherty Geosolutions }\end{array}$ \\
\hline $\begin{array}{r}\text { Is the invited manuscript for } \\
\text { consideration in a Special } \\
\text { Issue? : }\end{array}$ & N/A \\
\hline Keyword: & $\begin{array}{l}\text { Fragility curves, Vulnerability, Probabilistic analysis, Shallow landslides, } \\
\text { Rainfall }\end{array}$ \\
\hline
\end{tabular}




\title{
Fragility curves for rainfall-induced shallow landslides on transport networks
}

\author{
Karlo Martinović ${ }^{1,2}$, Cormac Reale ${ }^{1,3}$, Kenneth Gavin $^{1,3}$
}

${ }^{1}$ Gavin and Doherty Geosolutions, Nutgrove Office Park, Rathfarnham, Dublin 14, Ireland

${ }^{2}$ School of Civil Engineering, Newstead, University College Dublin, Ireland

${ }^{3}$ Faculty of Civil Engineering and Geosciences, TU Delft, Stevinweg 1, 2628 CN Delft, Netherlands

Email:kmartinovic@gdgeo.com, c.reale@tudelft.nl,k.g.gavin@tudelft.nl

Corresponding author: Karlo Martinović (Address: GDG, A2 Nutgrove Office Park, Rathfarnham, Dublin 14, Ireland. Phone: +353 1207 1000. Email: kmartinovic@gdgeo.com)

\begin{abstract}
Many of the earthworks assets on rail transport networks were constructed in the 1800's and have thus operated for periods far in excess of their expected service life. Incidences of failure, particularly shallow planar landslides are increasing, in part due to the effect of more intense and longer duration rainfall events. Network owners have difficulty in targeting scarce resources to reduce risk across networks. This paper proposes a methodology for developing fragility curves for rainfall induced landslides on transport networks. Fragility curves provide the probability of exceedance of different limit states for a given hazard considering a range of magnitudes. In this paper the vulnerability of slopes as expressed by a loss of performance, is quantified for rainfall events of various intensities and duration. The approach expands upon probabilistic slope stability analysis and provides a rational logical framework for considering how vulnerable a slope is to rainfall induced failure.
\end{abstract}

Keywords: fragility curves; vulnerability; probabilistic analysis; shallow landslides; rainfall; transport 


\section{Introduction}

In Europe there has been substantial variation in weather patterns over recent decades which affect the performance of engineered slopes. Since 1950 mean annual rainfall levels have increased by up to $70 \mathrm{~mm}$ per decade in Northern Europe and decreased by up to $70 \mathrm{~mm}$ per decade in Southern Europe (EEA 2012; Solomon 2007). Even in areas where rain levels are largely unchanged or annual values have decreased, a change of pattern where long, dry periods (which may allow ground cracking) are followed by short duration, high-intensity rainfall events can affect the incidence of slope failures. Many of the earthworks on Europe's rail networks were built more than 150 years ago at slope angles much steeper than those permitted in current design standards (Reale et al. 2016a). For over-steep slopes, those with no drainage or where lack of funding has constrained proper maintenance, rainfall induced slope failures can occur. The mechanism of failure results from the reduction of near surface soil suctions as a result of infiltrating water. These landslides can cause devastating direct and indirect damage (Zezere et al. 2007, 2008, Jaiswal et al. 2010; Klose et al. 2015). Asset owners need a methodology that allows scarce resources to be targeted across a network to minimise the vulnerability of the system to climate hazard sources such as rainfall. Hazard is defined as the probability that a particular threat (landslide) occurs within a given period of time (Fell et al. 2005). Vulnerability is commonly interpreted as the degree of loss accruing due to the failure of an element at risk, subject to a given hazard.

Figure 1 Shallow landslide on line between Ljubljana-Kamnik, Slovenia (picture courtesy of Slovenian Railways).

While substantial research has been carried out in the field of landslide risk assessment (Dai et al. 2002; Lee and Jones 2004; Fell et al. 2005), comparatively little attention has been given to the application of landslide risk assessment frameworks to transport infrastructure slopes (Gavin et al. 2016). Studies in the area (Fell et al. 2008; Corominas et al. 2014; Power et al. 2016) consider vulnerability in a relatively simple manner. Vulnerability indices typically vary depending on the element type, landslide type and the predicted landslide intensity. Vulnerability is usually measured using a matrix of indices comprised of non-dimensional factors between 0 and 1 , or by using fragility curves which express the conditional probability of reaching or exceeding a certain damage state, 
under a range of intensity measure values (Pitilakis and Fotopoulou 2011). Landslide intensity can be defined as the parameter which describes the destructiveness of a landslide (Hungr 1997). In fragility curves an intensity measure is a metric of either the landslide body (a physical characteristic) or a triggering action (the load magnitude), which quantifies the intensity of that landslide. Common examples include peak ground acceleration (PGA) or landslide volume. Damage states are determined based on the impact of a landslide on an asset, examples include the displacement of a slope or damage to a structural element. Depending on the method used to derive the fragility curves, the curves can be classified as empirical (formed using observations from previous landslide events), expert-judgment (formed using opinion), analytical (based on numerical modelling) or hybrid (Jeong and Elnashai 2007; Pitilakis and Fotopoulou 2011).

A number of researchers have developed fragility curves which consider the impact of landslides on structures. Fotopoulou and Pitilakis (2013a,b) developed a set of fragility curves for reinforced concrete structures situated on the crest of a slope subjected to an earthquake-triggered deep slowmoving landslide, using peak ground acceleration (PGA) as the intensity measure. Mavrouli and Corominas (2010), Haugen and Kaynia (2008) and Quan Luna et al. (2011) presented fragility curves for structures affected by rock falls and debris flows. In these approaches characteristics of the failure mass such as kinetic energy or impact pressure were used as intensity measures rather than the characteristics of the source event (rainfall, earthquake etc.). Altarejos-Garcia et al. (2014) presented a set of fragility curves investigating a sliding failure mode of an earth dams, with water level as the intensity measure.

A set of fragility curves for slopes on transport networks was developed by Argyroudis and Kaynia $(2014,2015)$. PGA was used as the intensity measure and damage states were based on the computed deformation of the slope crest. A similar approach was employed by Lagaros et al. (2009) and Tsompanakis et al. (2010), who also used PGA as an intensity measure. However unlike most examples of fragility curves, which typically use a physical damage descriptor to define damage states, the authors used target factors of safety from Greek seismic design codes as damage states. Winter et al. (2014) presented fragility curves for roads subject to blockage from debris flows 
originating on surrounding natural slopes. The empirical curves were developed following expert knowledge collated through questionnaires, and used pre-determined debris volumes as an intensity measure, without regard to the triggering event.

Wu (2015) developed fragility curves for shallow landslides triggered by both seismic loading and groundwater level related triggers. A simple translational failure model with the assumption that failure is triggered by the water table level rising from an impervious soil-bedrock interface was adopted. The change in height of the water table was taken as the intensity measure and no damage states were defined.

This brief review shows that the development of fragility curves is gaining traction for geotechnical engineering applications. The advantages of the approach include allowance for an explicit appraisal of the uncertainties associated with vulnerability modelling, and a possibility of presenting results for a wide range of loading. This makes fragility curves an attractive tool for carrying out risk assessments of large systems, such as major transport networks. However to date most research on vulnerability assessment related to slopes has focused on landslides triggered by earthquakes. Across the globe rainfall induced slope failures are a significant threat and their incidence is increasing as a result of climate change. This study develops a set of fragility curves to assess the vulnerability of engineered slopes and train operations to rainfall induced shallow landslides using probabilistic techniques. The resultant fragility curves assess the loss in slope performance, in terms of the slopes' remaining capacity when subjected to various rainfall scenarios. Pre-determined levels of slope performance are used to define damage indices, and rainfall loading is used as an intensity measure. 


\section{Development of fragility curves for rainfall induced shallow landslides}

In this section the development of the fragility curves is described. The process includes consideration of the failure mechanism, the limit states defined in the probabilistic analyses, the intensity measures and damage states.

\section{Rainfall induced shallow landslides: failure mechanism and assumed model}

Rainfall induced slope failure occurs as a result of infiltrating rainwater reducing near surface suctions in partially saturated soil masses. The failure surface usually presents as a shallow $(<3 \mathrm{~m})$ translational slip that forms parallel to the existing slope surface (Babu and Murthy 2005; Fredlund and Rahardjo 1993; Gavin and Xue 2009; Zhang et al. 2011). A statistical review of landslides that occurred on the Irish Rail network by Martinović et al. $(2016 a, b)$ identified shallow rainfall induced landslides as the most prevalent failure type. A simplified model of the mechanism assumes the wetting front depth as the failure surface (Gavin and Xue 2008). At the point of failure, suctions in the soil in the wetted zone above the failure surface reduce to some residual value (as full saturation is difficult to achieve in slopes where no ponding can occur). The magnitude of this residual suction depends largely on the porosity, particle size distribution and the clay content of the soil in question, see Fourie et al. (1999) and Springman et al. (2003).

Fredlund et al. (1978) expanded the traditional Mohr-Coulomb model to take into account the change in soil shear strength due to matric suction (negative pore-water pressures) see Equation 1.

$$
\tau=c^{\prime}+\left(\sigma_{n}-u_{a}\right) \tan \phi^{\prime}+\left(u_{a}-u_{w}\right) \tan \phi^{b}
$$

where: $\tau$ is unsaturated shear strength of the soil, c' is the effective cohesion, $\sigma_{n}$ is the total normal stress, $u_{a}$ is the pore-air pressure, $\phi^{\prime}$ is the angle of internal friction associated with the normal stress state variable $\sigma_{n}-u_{a}, u_{w}$ is the positive pore water pressure, $u_{a}-u_{w}$ is the matric suction and $\phi^{b}$ is the angle which describes the rate of increase in shear strength due to matric suction. Incorporating this expanded Mohr-Coulomb equation into an infinite slope model which assumes the failure depth and the wetting front depth are coincident, the Factor of Safety (FOS) of the slope can be obtained from Equation 2. 


$$
\text { FOS }=\frac{\mathrm{c}^{\prime}+\left(\mathrm{u}_{\mathrm{a}}-\mathrm{u}_{\mathrm{w}}\right) \tan \phi^{\mathrm{b}}+\gamma \mathrm{h} \cos ^{2} \alpha \tan \phi^{\prime}}{\gamma \mathrm{h} \sin \alpha \cos \alpha}
$$

Where: $\mathrm{h}$ is the wetting front depth, $\gamma$ is the unit weight of soil and $\alpha$ is the slope angle.

\section{Rainfall infiltration analysis}

While infiltration can be modelled using a variety of different methods, the approach derived by Richard (1931) for unsaturated flow, see Equation 3 is widely adopted.

$$
\frac{\delta}{\delta \mathrm{x}}\left(\mathrm{k}_{\mathrm{x}} \frac{\delta \mathrm{H}}{\delta \mathrm{x}}\right)+\frac{\delta}{\delta \mathrm{y}}\left(\mathrm{k}_{\mathrm{y}} \frac{\delta \mathrm{H}}{\delta \mathrm{y}}\right)+\mathrm{Q}=\frac{\delta \theta}{\delta \mathrm{t}}
$$

Where: $\mathrm{H}$ is the total head, $\mathrm{k}_{\mathrm{x}}$ is the hydraulic conductivity in $\mathrm{x}$ (horizontal) direction, $\mathrm{k}_{\mathrm{y}}$ is the hydraulic conductivity in the $\mathrm{y}$ (vertical) direction, $\mathrm{Q}$ is the applied boundary flux, $\theta$ is the volumetric water content and $t$ is time. This method has been applied in this paper to calculate how soil suction changes over time within the slope as rain water infiltrates. In this research this approach was implemented in the commercial finite element software, Geostudio SEEP/W 2007.

\section{Probabilistic analysis}

Probabilistic techniques are ideally suited to the analysis of rainfall induced failures as both the load (disturbing force - rainfall) and the resistance (which depends on soil suction) vary temporally as a result of climate (Babu and Murthy 2009; Xue and Gavin 2007; Gavin and Xue 2009; Reale et al. 2016b). To carry out the analysis, a probabilistic distribution is assigned to every input variable of note allowing any uncertainty in design values to be accounted for explicitly within stability calculations. This results in a more meaningful, rational framework for interpreting safety than traditional deterministic design which assumes fixed point values (Reale et al. 2015). The performance function $g(X)$ or limit state function of a slope can be expressed as the difference between a slopes capacity (C) and its demand (D), see Equation 4.

$$
g(X)=(C-D)\left\{\begin{array}{l}
>0, \text { safe state } \\
=0, \text { limit state } \\
<0, \text { failure state }
\end{array}\right.
$$

Following on from this the performance function can be expressed as follows: 


$$
g(X)=\text { FOS }-1
$$

Where the FOS in this study is defined by Equation 2. The probability of failure $\left(P_{f}\right)$ is then defined as the probability of the performance function being less than or equal to zero, see Equation 6.

$$
P_{f}=P[g(X) \leq 0]
$$

In this paper Equation 6 is solved using the popular Monte Carlo Simulation (MCS) method. MCS is a technique often used to simulate the probability density function of a performance function. It works by assigning probability density functions to each of the input variables and then randomly generating $n$ sample values from these distributions. The performance function is then evaluated deterministically $n$ times, once for each set of input values, generating a separate value of the performance function, $\mathrm{g}(\mathrm{x})$ for every set of input values. The output of these multiple analyses is then a distribution of likely values of the performance function. If a sufficient number of samples are generated, summing the number of events less than the limit state is akin to integration, in which case the probability of failure can be evaluated by Equation 7 .

$$
\mathrm{P}_{\mathrm{f}}=\frac{\text { number of failure events }}{\text { number of samples }}
$$

The reliability index $\beta$ can then be calculated as the number of standard deviations between the mean of the performance function and the failure zone.

(8) $\beta=\frac{E[g(X)]}{\sigma[\mathrm{g}(\mathrm{X})]}$

Assuming the factor of safety follows an approximately normal distribution then the reliability index $\beta$ is related to the probability of failure, $P_{f}$, by Equation [9].

$$
\mathrm{P}_{\mathrm{f}}=\Phi(-\beta)
$$

\subsection{Damage states and intensity measure}

The fragility curves developed in this study express the probability of reaching or exceeding certain damage states which are here defined by three target reliability indices $\left(\beta_{\mathrm{T}}\right)$, see Figure 2 and Table 1 . 
In asset management, target reliability and target probabilities of failure $\left(\mathrm{P}_{\mathrm{fs}}\right)$ are commonly used as a means of measuring an asset's performance, see Chowdhury and Flentje (2003). Target reliability indices and $\mathrm{P}_{\mathrm{fs}}$ are typically determined based on the potential consequences arising from failure of an element (Salgado and Kim 2013). These target reliability indices represent the minimum acceptable limit that categorise a slopes performance into a certain condition, ranging from hazardous to good. The Transportation Research Board (Santamarina et al. 1992) and the U.S. Army Corps of Engineers (USACE 1999) have published tables of recommended target reliabilities and target probabilities of failure for engineered slopes, with the recommended safety level determined by the intended end use of the structure. The three $\beta_{\mathrm{T}}$ values in Table 1 were selected following these recommendations. Damage states as defined through target reliability levels represent a loss in slope capacity and hence performance. Reaching a particular damage state could be used to prompt an infrastructure manager to react (e.g. lower the train speed or temporarily stop the train operations), which causes indirect losses to train operations. This way fragility curves determine the vulnerability of slopes and train operations to a rainfall induced landslide hazard.

In this study, rainfall (of a given intensity and duration) is taken as an intensity measure. Rainfall duration is depicted on the x-axis of the fragility curves as opposed to total rainfall. This approach is preferred as the same total rainfall value can result from many different combinations of rainfall intensities and durations, and the ensuing infiltration in the soil is different for each of these combinations (Xue and Gavin 2008). Given that this case study assumes a constant rainfall intensity of $5 \mathrm{~mm} / \mathrm{h}$, total rainfall can be acquired by getting the product of rainfall intensity and rainfall duration at the point in question.

\section{Figure 2 Graphical representation depicting the relationship between the probability of failure and the reliability index}

\section{Summary of the method to derive fragility curves}

The approach used in this study builds a fragility curve by calculating the probability that the reliability index from slope stability calculations will be equal or smaller than the target reliability index, for a range of rainfall durations. The procedure is as follows: 
1. An infiltration analysis was carried out on a test slope using the commercial finite element software SEEP/W to model the influx of water into the slope with time. The progression of the wetting front over time was tracked by monitoring the time taken for each element to reach its residual suction.

2. The wetting front depth and corresponding time was then inputted to a bespoke reliability module. Within the reliability module the slope was analysed probabilistically at the wetting front depth for each time increment using the infinite slope formulation presented in Eqn 10a as the limit state, where the boundary of the failure zone is described by Eqn 10b (see Figure 1). Distributions were applied to the relevant soil parameters using values taken from the literature. A Monte Carlo simulation was used to model how the factor of safety distributions change as the wetting front progresses.

3. Different rainfall intensities were modelled and the resultant probability of failure data (considering all three potential damage states) was plotted with time to determine the fragility curves. So for each rainfall intensity and duration combination considered, three realisations of probability of failure and reliability index are determined corresponding to the three damage states.

$$
\operatorname{FOS}(\mathrm{t})=\frac{\mathrm{c}^{\prime}+\left(\mathrm{u}_{\mathrm{a}}-\mathrm{u}_{\mathrm{w}}\right) \tan \phi^{\mathrm{b}}+\gamma \mathrm{h}(\mathrm{t}) \cos ^{2} \alpha \tan \phi^{\prime}}{\gamma \mathrm{h} \sin \alpha \cos \alpha}
$$

$g(X)=\operatorname{FOS}(\mathrm{t})-1$

This paper considers the material point variations of geotechnical strength properties and soil unit weight, in addition it also considers the variation of soil suction at the wetting front boundary. An alternative way to represent this is to consider the variability of the soil's hydraulic properties which govern the rainfall infiltration process (Zhang et al. 2016).

Recent advances in the state of the art in unsaturated slope stability also consider the effects of spatial variability of saturated hydraulic conductivity (Santoso et al. 2010, 2011a, Dou et al. 2014), and the 
probabilistic modelling of soil water characteristic curves (SWCC) (Phoon et al. 2010, Santoso et al. 2011b). This is not considered within this paper as the purpose of this paper is to produce a series of fragility curves which could be used for general groups of transport infrastructure slopes that have similar properties, and a simplified procedure of applying the variability to the final residual suction was used here. Nevertheless the variability and probabilistic modelling of hydraulic parameters are mentioned here to alert the reader to its importance for individual sites of concern.

\section{Case study: typical slope on Irish rail network}

The methodology for the construction of fragility curves described in the previous section was applied to the analysis of slopes on the Irish Rail network. One of the features of the approach is that assets (slopes) along the network could be grouped into categories with similar characteristics (soil, slope angle height etc.). The earthworks (cuttings and embankments) were constructed more than 150 years ago. Based on LiDAR data (Martinovic et al. 2016a) report that the slope angle on the network can be described approximately with a normal distribution can be observed with a mean slope angle value of $40^{\circ}$ and a median value of $38^{\circ}$, See Figure 3 . Almost $25 \%$ of slopes on the network have a slope angle of $45^{\circ}$ or above and a number of rainfall induced failures appear to occur on slopes at around this critical angle. For this reason a slope angle of $45^{\circ}$ was chosen for demonstration purposes.

Figure 3 Frequency and cumulative distribution of soil slope angles on Irish rail network

Glacial till (boulder clay) covers almost $50 \%$ of the ground surface in the Republic of Ireland (Fealy 2009) and are the most commonly encountered soil type on the Irish Rail network. Irish glacial tills have been extensively characterised (Hanrahan 1977; Lehane and Faulkner 1998; Long and Menkiti 2007). Typical material parameters required for the rainfall infiltration and slope stability calculations inferred from the literature are summarised in Table 2. Coefficients of variations (COV) were also assigned, where applicable, for probabilistic calculations based on the recommendations of Phoon and Kulhawy (1999). Normal distributions were used to define the geotechnical strength parameters and unit weight, as suggested by Lumb (1966), Hassan and Wolff (1999) and Babu and Murthy (2005). The probabilistic assessment of hydraulic properties is also of importance for rainfall-induced shallow 
slides (Santoso et al. 2011a). To account for this, the residual soil suction was considered to be a variable.

The mean value of the angle of internal friction assigned for the glacial till relates to the constant volume friction angle or large-strain value for this non strain-softening soil. A $\varphi^{\mathrm{b}}$ value equal to the internal angle of friction was adopted following recommendations by Gan et al. (1988) for soils approaching saturation. The effective cohesion of Irish glacial tills is close to zero (as the clay particle sized portion of the material is largely comprised of rock flour developed as a result of glacial abrasion and there are no clay minerals present). As a result a small value of $1 \mathrm{kN} / \mathrm{m}^{2}$ was used in order to investigate the effect of the cohesion magnitude in a subsequent sensitivity analysis. Hughes et al. (2016) reported measurements of hydraulic properties of Irish till from an engineered slope affected by fracturing and weathering that were adopted in this study. Because of a dearth of information of the unsaturated behaviour for Irish glacial tills, a soil water characteristic curve (SWCC) of a well-characterised (and geologically similar) Canadian glacial till (Vanapalli et al. 1996; Khanzode et al. 2002; Oh and Vanapalli 2010) was used in this study. This SWCC was also used to obtain the unsaturated hydraulic conductivity curve.

The slope was modelled with an impervious lower boundary running parallel to the slope surface at a depth of $4 \mathrm{~m}$, see Figure 4. Both vertical boundaries were also set as impervious (zero flux) boundaries. Infinite elements were assumed on the lower (right) vertical boundary to avoid modelling an impermeable obstacle. The slope section was then divided into a dense quadrilateral element mesh with vertical sides. In general a relatively small element size of $0.2 \mathrm{~m}$ was used in order to obtain a clear picture of the wetting front progression with depth. A refined mesh $(0.025 \mathrm{~m}$ element size $)$ was implemented to a depth of $0.1 \mathrm{~m}$ below the slope surface in order to more accurately capture the early wetting front progression.

Figure 4 Finite element model mesh

At the start of the analysis a constant initial suction of $20 \mathrm{kPa}$ was assumed throughout the slope. The Irish Meteorological Service operates a weather warnings system, based on a traffic light system with 
red representing severe. A red weather warning is issued when total anticipated rainfall is expected to exceed $50 \mathrm{~mm}$ in 12 hours $(4.17 \mathrm{~mm} / \mathrm{h})$ or $70 \mathrm{~mm}$ in 24 hours $(2.92 \mathrm{~mm} / \mathrm{h})$. Current climate predictions for Ireland forecast an increase in intense or prolonged precipitation events (Sweeney et al. 2008). A constant rainfall intensity of $5 \mathrm{~mm} / \mathrm{h}$ was applied in the model as a unit flux upper boundary condition to model a rainfall event approximately $20 \%$ above the current severe level. As this rainfall intensity is greater than the saturated permeability of the soil, the infiltration capacity will continue to reduce with time until positive pore pressures start to appear on the surface of the model, indicating water ponding. Given ponding cannot occur on a steep slope the upper boundary condition is at this point changed to a constant head condition having a pressure head of zero, following the approach suggested by Collins and Znidarcic (2004) and Le et al. (2015). The wetting front was defined when the suction reached $3 \mathrm{kPa}$ the specified residual value and the relationship between rainfall duration and wetting front depth was recorded for the probabilistic analyses.

\section{Results and discussion}

Following the approach described in the preceding sections, fragility curves for low, medium and high damage states were constructed for the test slope. Using the mean geotechnical parameter values and COVs outlined in Table 2, in combination with wetting front depths and corresponding rainfall durations, obtained through the SEEP/W rainfall infiltration analysis, a Monte Carlo probabilistic slope stability analysis was performed and the resulting fragility curves are presented in Figure 5.

\section{Figure 5 Fragility curves for case study slope}

The curves show that during the first five hours of rainfall the probability of exceeding any of the damage states is virtually zero. For longer rainfall durations, the probability of exceedance rises steadily, together with the time differences between the damage states. For example, after 12-hours of rainfall the probability of exceeding the low damage state $\left(\beta_{\mathrm{T}}=2\right)$ is 0.82 , while the probability of reaching the high damage state $\left(\beta_{\mathrm{T}}=1\right)$ is approximately 0.47 . For rainfall durations longer than 18 hours, the probabilities of exceedance from all three damage states are in excess of 0.9 and thereafter increase asymptotically towards 1. 
As a relatively large number of inputs are required to construct the fragility curves, the extent of each parameter's influence on the final results should be assessed. A sensitivity analysis of this form enables end users to identify which input parameters are of greater importance and therefore resources can be committed to obtaining more accurate distributions of these key variables. Ultimately this provides recommendations on slope typology, which will determine the number of fragility curves required for complete coverage of the network (Argyroudis and Kaynia 2014). For this process a bench mark reliability index was calculated, assuming a wetting front depth of $1 \mathrm{~m}$ (corresponding to the average depth of failures seen across the network). The input parameter values were then adjusted by $\pm 10 \%$ and the resultant reliability indices plotted in a tornado plot, see Figure 6 . The results unsurprisingly show that slope angle and soil friction angle are the major drivers of slope reliability, with the effective cohesion and residual suction having significantly less influence. Naturally this is a point variation and hence cannot capture the relative importance of various parameters over their entire range. Nevertheless the results are meaningful as they capture the relative importance of parameters over the ranges typically encountered on Irish Rail earthworks, for a typical failure depth. Changing the COVs of the parameters was shown to have a much less significant effect when compared to changes in mean values. However, it should be noted that some sites will have significantly higher variations, at which point the relative importance of COVs will become more important. The results indicate that when creating a typology classification for glacial till slopes, slopes should be classified into a large number of sub-groups based on relatively small slope angle increments, with each group attributed a family of fragility curves.

Figure 6 Sensitivity analysis for a selection of input parameters: slope angle $(\alpha)$, internal angle of friction $(\varphi)$, the angle describing the rate of increase in shear strength due to matric suction ( $\varphi b$ ), residual suction (ua-uw), effective cohesion (c') and their respective coefficients of variations (COVs)

Developing a full suite of fragility curves by varying input values of a particular parameter will bring more insight into the effects of design point variation on a single parameter. An example of this can be seen in Figure 7 where fragility curves for all three damage states are developed for a slope with the same material parameters (Table 2) but with a slope angle between $40^{\circ}$ and $50^{\circ}$. This range was 
chosen as $44 \%$ of all soil slopes on the Irish rail network have a slope angle above $40^{\circ}$, whilst only $12 \%$ have a slope angle above $50^{\circ}$. Interestingly the influence of slope angle on rainfall duration required to develop some probability of failure appears to be non-linear, as the sets of fragility curves appear to be grouped closer together at steeper slope angles and further apart at shallower inclinations. This indicates that the influence that slope angle has on vulnerability increases as the slope angle increases. This is because at steeper slope angles the failure depth (wetting front) is lower, as a smaller volume of soil needs to be mobilised to overcome equilibrium.

Figure 7 Fragility curves for slope with $40^{\circ}, 45^{\circ}$ and $50^{\circ}$

While a change in infiltration input parameters (saturated permeability, rainfall intensity, initial and residual suctions) will not affect the percent change of reliability index in Figure 4, it will change the time of arrival of the wetting front, which subsequently will affect the shape of the fragility curves. To appreciate this, fragility curves for a rainfall intensity of $3 \mathrm{~mm} / \mathrm{h}$, akin to the current lower-bound red warning level rainfall intensity, are compared together with the fragility curves for the rainfall intensity of $5 \mathrm{~mm} / \mathrm{h}$ in Figure 8 .

It is clear that the fragility curves for the lower intensity rainfall are displaced significantly to the right, as the wetting front takes a much longer time to develop. However, once the degradation process initiates the curves have a very similar shape, as the infiltration process following wetting front development largely depends on the saturated permeability value. This will hold true only for cases where the rainfall intensity is higher than the saturated permeability.

Figure 8 Fragility curves for rainfall intensities of $3 \mathrm{~mm} / \mathrm{h}$ and $5 \mathrm{~mm} / \mathrm{h}$

Given the saturated permeability of soil is one of the most variable and uncertain parameters, the influence of this parameter on the shape of the fragility curve is considered in Figure 8. Values for saturated permeability were taken as 50\% higher and $50 \%$ lower than the initial case study value, amounting to $1.5 \times 10^{-6} \mathrm{~m} / \mathrm{s}$ and $5 \times 10^{-7} \mathrm{~m} / \mathrm{s}$ respectively. The values are seen to have a significant impact on the rainfall duration required for a failure to occur. In Figure 9, the lower value causes a slower advance of the wetting front, resulting in lower probabilities of exceeding damage states. 
Conversely, higher saturated permeability's facilitate downward seepage and as a result fragility curves are much steeper. It should be noted however that this conclusion is not universal as for coarser soils with a different SWCC and high permeability a wetting front might not form at all.

\section{Figure 9 Fragility curves for three different values of saturated permeability}

The analyses presented show that the shape of the fragility curve depends on both environmental loading (rainfall intensity and duration) and soil parameters. In addition to the parameters considered the shape of a fragility curves will also depend on inputs including the initial soil suction, SWCC and other parameters. This makes the initial evaluation of geotechnical parameters and their expected ranges an important step in the development of fragility curves for a given network.

\section{Validation}

Since the damage states considered in this approach are defined in terms of loss of slope capacity, it is extremely difficult to establish the veracity of the developed fragility curves. No observable physical features can reliably be linked to a certain level of performance, especially for shallow rainfallinduced landslides which often occur rapidly with no warning sign. However, historical failures can be used as an indirect verification measure, given the assumption that at the time of the slope failure all three damage states are expected to have a significant probability of having been surpassed.

To verify the proposed fragility curves, four high-profile landslides that recently occurred on the Irish Rail earthworks (V1 to V4) have been examined. All four of landslides occurred in glacial till slopes during significant rainfall events. Some details describing the slopes and rainfall events are given in Table 3. The local rainfall data from the failure dates in question was obtained from The Irish Meteorological Service. Fragility curves were calculated for each verification case, using the geometry and rainfall loading data. For simplicity, an average rainfall intensity was assumed for each case. As no site-specific geotechnical data was available for any of these cases, the fragility curves were developed using the same geotechnical parameters applied for the virtual case study. 
Fragility curves for low (full-lines) and high damage state (dashed-lines) are presented in Figure 10 for each validation case. Curves for the medium damage state were omitted for increased clarity. Failures are plotted as single events at the top of the graph, i.e. they are assigned a $100 \%$ probability at the time of failure.

Figure 10 Fragility curves for verification cases

The range of probability values at the time of the failure were then observed for each validation case study. For three out of four cases, the probability of exceeding the low damage state was between $67 \%$ and $90 \%$, while the probability of exceeding the high damage state ranged from $29 \%$ to $62 \%$. Validation case 3 exhibited somewhat lower values (42\% for the low DS and $12 \%$ for the high DS), these are still relatively high failure values and can be considered reasonable when one reflects that the probability of exceeding any of the damage states was practically zero for over 12 hours.

For verification purposes, a slope either fails or it does not, it is impossible to tell what the probability of failure was before it failed. Therefore all we can gauge from this verification exercise is that the failure events happened after a relatively long rainfall duration, not during the early infiltration period where the slope performance is scarcely affected. Given the large range of possible rainfall duration and the narrowness of the strips where each fragility curve abruptly rises from 0 to 1 , the verification results show a reasonable match. It is assumed that an even better match would have been obtained if more site-specific data was available. For instance, all failures occurred following a long period of inclement weather, so the actual initial suction was more than likely lower than the assumed initial suction of $20 \mathrm{kPa}$. Other sources of discrepancy are asset-specific features such as drainage type and condition or vegetation cover. These features can influence the path water takes during infiltration and the modelling of these influences is less straightforward.

The verification results are consistent, with all four cases falling inside the narrow strip where curves rise from 0 to 1 . Since all verification cases were calculated using the same set of soil parameters estimated from the literature, this consistency confirms the applicability of fragility curves for solving real life asset management problems, where infrastructure managers typically have to resort to 
grouping assets into and estimating soil properties due to the infeasibility of carrying out detailed soil investigations for each asset.

\section{Conclusions}

To accurately assess the risk of landslides on a large transport network there needs to be some methodology for considering the consequence of a certain triggering event. Fragility curves provide a rational, logical framework for quantifying the degree of damage to elements at risk, thereby allowing one to understand the impact and hence consequence of certain events.

This paper presents a comprehensive methodology for developing fragility curves for soil slopes subject to rainfall induced shallow landslides. The loading event or intensity measure is a product of rainfall intensity and duration, while damage states are represented by target reliability indices. The assumed failure mode is a translational shallow slide, following shear strength reduction caused by infiltrating rainwater leading to a decrease of soil suction. The fragility curves are modelled using Monte Carlo simulations to determine the change in reliability with rainfall duration. The fragility curves therefore monitor the change in slope capacity with rainfall and chart the probability of the slope passing certain critical thresholds which correspond to a loss in performance. These thresholds are target reliabilities and can be viewed as serviceability limit states. While they may not correspond with ultimate failure, they represent the transition between various safety levels. In this fashion fragility curves can be used by the operators of transport networks in conjunction with detailed weather forecasts to justify reducing speed or closing services when the risk of failure exceeds allowable limits.

A verification procedure has been carried out by back-analysing four high-profile historical failures from the Irish Rail network. Fragility curves for these four sites show a high degree of agreement with the actual time of failure and thus confirm the applicability of the developed approach.

This methodology can be used for the assessment of both cuttings and embankments on road, rail and water transport networks where the governing failure mechanism is connected to the loss of matric 
suction in thick soil deposits. The soil conditions and slope geometries present on a specific network will determine the number of different fragility curves needed to accurately assess the vulnerability of the entire network.

\section{Acknowledgments}

The research is supported by the Irish Research Council Employment Based Postgraduate Programme and the Horizon 2020 Project Destination Rail (Project No 636285). The authors would like to thank Irish Rail for the permission to use the data, particularly Cathal Mangan, Sharon Callanan and Catherine Joyce.

\section{References}

Altarejos-García, L., Silva-Tulla, F., Escuder-Bueno, I., and Morales-Torres, A. 2014. Practical risk assessment for embankments, dams, and slopes. In Risk and Reliability in Geotechnical Engineering (pp. 437-469). CRC Press.

Argyroudis, S., and Kaynia, A.M. 2014. Fragility functions of highway and railway infrastructure. In SYNER-G: typology definition and fragility functions for physical elements at seismic risk (pp. 299-326).

Argyroudis, S., and Kaynia, A.M. 2015. Analytical seismic fragility functions for highway and railway embankments and cuts. Earthquake Engineering and Structural Dynamics, 44(11):1863-1879.

Babu, G.S., and Murthy, D. 2005. Reliability analysis of unsaturated soil slopes. Journal of Geotechnical and Geoenvironmental Engineering, 131(11): 1423-1428.

Chowdhury, R., and Flentje, P. 2003. Role of slope reliability analysis in landslide risk management. Bulletin of Engineering Geology and the Environment, 62(1): 41-46.

Collins, B.D., and Znidarcic, D. 2004. Stability analyses of rainfall induced landslides. Journal of Geotechnical and Geoenvironmental Engineering, 130(4): 362-372. 
Corominas, J., Van Westen, C., Frattini, P., Cascini, L., Malet, J.P., Fotopoulou, S., Catani, F., Van Den Eeckhaut, M., Mavrouli, O., Agliardi, F. and Pitilakis, K. 2014. Recommendations for the quantitative analysis of landslide risk. Bulletin of engineering geology and the environment, 73(2): 209-263.

Dai, F.C., Lee, C.F., and Ngai, Y.Y. 2002. Landslide risk assessment and management: an overview. Engineering geology, 64(1): 65-87.

Dou, H.Q., Han, T.C., Gong, X.N., and Zhang, J. 2014. Probabilistic slope stability analysis considering the variability of hydraulic conductivity under rainfall infiltration-redistribution conditions. Engineering Geology, 183:1-13.

El-Ramly, H., Morgenstern, N.R., and Cruden, D.M. 2002. Probabilistic slope stability analysis for practice. Canadian Geotechnical Journal, 39(3): 665-683.

European Environment Agency 2012. Climate change, impacts and vulnerability in Europe 2012. EEA Report no 12/2012, ISBN: 978-92-9213-346-7

Fealy, R. M., Green, S., Loftus, M., Meehan, R., Radford, T., Cronin, C., and Bulfin, M. 2009. Teagasc/EPA soil and subsoils mapping project. Final Report, 1. Dublin

Fell, R., Ho, K.K., Lacasse, S., and Leroi, E. 2005. A framework for landslide risk assessment and management. Landslide risk management, pp.3-25.

Fell, R., Corominas, J., Bonnard, C., Cascini, L., Leroi, E., and Savage, W.Z. 2008. Guidelines for landslide susceptibility, hazard and risk zoning for land-use planning. Engineering Geology, 102(3): 99-111.

Fotopoulou, S.D., and Pitilakis, K.D. 2013a. Vulnerability assessment of reinforced concrete buildings subjected to seismically triggered slow-moving earth slides. Landslides, 10(5): 563582. 
Fotopoulou, S.D., and Pitilakis, K.D. 2013b. Fragility curves for reinforced concrete buildings to seismically triggered slow-moving slides. Soil Dynamics and Earthquake Engineering, 48: $143-161$.

Fourie, A.B., Rowe, D., and Blight, G.E. 1999. The effect of infiltration on the stability of the slopes of a dry ash dump. Geotechnique, 49(1): 1-13.

Fredlund, D.G., Morgenstern, N.R., and Widger, R.A. 1978. The shear strength of unsaturated soils. Canadian geotechnical journal, 15(3): 313-321.

Fredlund, D.G., and Rahardjo, H. 1993. Soil mechanics for unsaturated soils. John Wiley and Sons.

Gan, J.K.M., Fredlund, D.G., and Rahardjo, H. 1988. Determination of the shear strength parameters of an unsaturated soil using the direct shear test. Canadian Geotechnical Journal, 25(3): 500510.

Gavin, K., and Xue, J. 2008 A simple method to analyse infiltration into unsaturated slopes', Computers and Geotechnics. 35(2): 223-230.

Gavin, K., and Xue, J. 2009. Use of a genetic algorithm to perform reliability analysis of unsaturated soil slopes. Géotechnique, 59(6): 545-549

Gavin, K., Martinović, K., Reale, C., Bacic, M., and Wooff, C. 2016. Use of Risk Assessment Frameworks for the Management of Transport Infrastructure Slopes in Europe, Quarterly Journal of Engineering Geology and Hydrogeology, submitted.

Hanrahan, E.T. 1977. Irish glacial till: origin and characteristics (No. RC 164 Monograph).

Hassan, A.M., and Wolff, T.F. 1999. Search algorithm for minimum reliability index of earth slopes. Journal of Geotechnical and Geoenvironmental Engineering, 125(4): 301-308.

Haugen, E.D., and Kaynia, A.M. 2008. Vulnerability of structures impacted by debris flow. Landslides and engineered slopes. Taylor and Francis, London, pp.381-387. 
Hughes, D.A.B., Clarke, G.R.T., Harley, R.M.G., and Barbour, S.L. 2016. The impact of hydrogeology on the instability of a road cutting through a drumlin in Northern Ireland. Quarterly Journal of Engineering Geology and Hydrogeology, 49(1): 92-104.

Hungr, O. 1997. Some methods of landslide hazard intensity mapping. Landslide risk assessment. Balkema, Rotterdam, pp.215-226.

Jaiswal, P., Van Westen, C.J., and Jetten, V. 2010. Quantitative assessment of direct and indirect landslide risk along transportation lines in southern India. Natural Hazards and Earth System Sciences, 10(6): 1253-1267.

Jeong, S.H., and Elnashai, A.S. 2007. Probabilistic fragility analysis parameterized by fundamental response quantities. Engineering Structures, 29(6), pp.1238-1251.

Khanzode, R.M., Vanapalli, S.K., and Fredlund, D.G. 2002. Measurement of soil-water characteristic curves for fine-grained soils using a small-scale centrifuge. Canadian geotechnical journal, 39(5): 1209-1217.

Klose, M., Damm, B., and Terhorst, B. 2015. Landslide cost modeling for transportation infrastructures: A methodological approach. Landslides, 12(2): 321-334.

Lagaros, N.D., Tsompanakis, Y., Psarropoulos, P.N., and Georgopoulos, E.C. 2009. Computationally efficient seismic fragility analysis of geostructures. Computers and Structures, 87(19): 11951203.

Le, T.M.H., Gallipoli, D., Sánchez, M., and Wheeler, S. 2015. Stability and failure mass of unsaturated heterogeneous slopes. Canadian Geotechnical Journal, 52(11): 1747-1761.

Lee, E.M., and Jones, D.K.C. 2004. Landslide risk assessment. Thomas Telford Books, London.

Lehane, B., and Faulkner, A. 1998. Stiffness and strength characteristics of a hard lodgement till. The geotechnics of hard soil \pm soft rocks (eds Evangelista and Picarelli), pp.637-646. 
Long, M., Menkiti, C. 2007. Geotechnical characteristics of Dublin Glacial Till. Géotechnique, 57(7): 595-611.

Lumb, P. 1966. The variability of natural soils. Canadian Geotechnical Journal, 3, 74-97.

Martinović, K., Gavin, K., and Reale, C. 2016a. Assessing the vulnerability of Irish Rail network earthworks. Transportation Research Procedia, 14: 1904-1913.

Martinović, K., Gavin, K., and Reale, C. 2016b. Development of a landslide susceptibility assessment for a rail network. Engineering Geology, 215, pp.1-9. doi:10.1016/j.enggeo.2016.10.011

Mavrouli, O., and Corominas, J. 2010. Rockfall vulnerability assessment for reinforced concrete buildings. Natural Hazards and Earth System Sciences, 10(10): 2055-2066.

Oh, W.T., and Vanapalli, S.K. 2010. Influence of rain infiltration on the stability of compacted soil slopes. Computers and Geotechnics, 37(5): 649-657.

Phoon, K.K., and Kulhawy, F.H. 1999. Characterization of geotechnical variability. Canadian Geotechnical Journal, 36(4): 612-624.

Phoon, K.K., Santoso, A., and Quek, S.T. 2010. Probabilistic analysis of soil-water characteristic curves. Journal of Geotechnical and Geoenvironmental Engineering, 136(3):445-455.

Pitilakis, K., Fotopoulou, S. (eds) 2011. Physical vulnerability of elements at risk to landslides: methodology for evaluation, fragility curves and damage states for buildings and lifelines. SafeLand Deliverable 2.5.

Power, C., Mian, J., Spink, T., Abbott, S., and Edwards, M. 2016. Development of an Evidence-based Geotechnical Asset Management Policy for Network Rail, Great Britain. Procedia Engineering, 143: 726-733. http://doi.org/10.1016/j.proeng.2016.06.112

Quan Luna, B., Blahut, J., Van Westen, C.J., Sterlacchini, S., van Asch, T.W., and Akbas, S.O. 2011. The application of numerical debris flow modelling for the generation of physical vulnerability curves. Natural hazards and earth system sciences, 11(7): 2047-2060. 
Reale, C., Xue, J.F., Pan, Z., and Gavin, K. 2015. Deterministic and probabilistic multi-modal analysis of slope stability. Computers and Geotechnics, 66(5): 172-179.

Reale, C., Gavin, K., Xue, J.F., and Prendergast, L.J. 2016a. Multi-modal Reliability Analysis of Slope Stability. Transportation Research Procedia, 14: 2468-2476.

Reale, C., Xue, J., and Gavin, K. 2016b. System reliability of slopes using multimodal optimisation. Géotechnique, 66(5), pp.413-423.

Richards, L.A. 1931. Capillary conduction of liquids through porous mediums. Journal of Applied Physics, 1(5): 318-333.

Salgado, R., and Kim, D. 2013. Reliability analysis of load and resistance factor design of slopes. Journal of Geotechnical and Geoenvironmental Engineering, 140(1): 57-73.

Santamarina, J.C., Altschaeffl, A.G., and Chameau, J.L. 1992. Reliability of slopes: incorporating qualitative information (abridgment). Transportation Research Record, (1343).

Santoso, A., Phoon, K.K., and Quek, S.T. 2010. Flow of Water through Spatially Heterogeneous Soil, Proceedings, Seventeenth Southeast Asian Geotechnical Conference, Taiwan. Volume 2, 249 $-253$

Santoso, A.M., Phoon, K.K., and Quek, S.T. 2011a. Effects of soil spatial variability on rainfallinduced landslides. Computers \& Structures, 89(11): 893-900.

Santoso, A., Phoon, K.K., and Quek, S.T. 2011b. Probability Models for SWCC and Hydraulic Conductivity. Proceedings, Fourteenth Asian Regional Conference on Soil Mechanics and Geotechnical Engineering (14ARC), Hong Kong, China, 23-27 May 2011.

Solomon, S. ed. 2007. Climate change 2007-the physical science basis: Working group I contribution to the fourth assessment report of the IPCC (Vol. 4). Cambridge University Press.

Springman, S., Jommi, C., and Teysseire, P. 2003. Instabilities on moraine slopes induced by loss of suction: a case history. Géotechnique, 53(1): 3-10. 
Sweeney, J., Albanito, F., Brereton, A., Caffarra, A., Charlton, R., Donnelly, A., and Murphy, C. 2008. Climate Change-Refining the Impacts for Ireland: STRIVE Report (2001-CD-C3-M1) ISBN: 978-1-84095-297-1.

Tsompanakis, Y., Lagaros, N.D., Psarropoulos, P.N., and Georgopoulos, E.C. 2010. Probabilistic seismic slope stability assessment of geostructures. Structure and Infrastructure Engineering, 6(1-2): 179-191.

U.S.A.C.E. 1999. ETL 1110-2-556. Risk-based analysis in geotechnical engineering for support of planning studies, Appendix A. U.S. Army Corps of Engineers Document

Vanapalli, S.K., Fredlund, D.G., Pufahl, D.E., and Clifton, A.W. 1996. Model for the prediction of shear strength with respect to soil suction. Canadian Geotechnical Journal, 33(3): 379-392.

Wang, Y., Cao, Z., and Au, S.K. 2010. Efficient Monte Carlo simulation of parameter sensitivity in probabilistic slope stability analysis. Computers and Geotechnics, 37(7):1015-1022.

Winter, M.G., Smith, J.T., Fotopoulou, S., Pitilakis, K., Mavrouli, O., Corominas, J., and Argyroudis, S. 2014. An expert judgement approach to determining the physical vulnerability of roads to debris flow. Bulletin of Engineering Geology and the Environment, 73(2): 291-305.

Wu, X.Z. 2015. Development of fragility functions for slope instability analysis. Landslides, 12(1): $165-175$.

Xue, J.F., and Gavin, K. 2007. Simultaneous determination of critical slip surface and reliability index for slopes. Journal of Geotechnical and Geoenvironmental Engineering, 133(7): 878-886.

Xue, J., and Gavin, K. 2008. Effect of rainfall intensity on infiltration into partly saturated slopes. Geotechnical and Geological Engineering, 26(2): 199-209.

Zêzere, J.L., Oliveira, S.C., Garcia, R.A.C., and Reis, E. 2007. Landslide risk analysis in the area North of Lisbon (Portugal): evaluation of direct and indirect costs resulting from a motorway disruption by slope movements. Landslides, 4(2): 123-136. 
Zêzere, J.L., Garcia, R.A.C., Oliveira, S.C., and Reis, E. 2008. Probabilistic landslide risk analysis considering direct costs in the area north of Lisbon (Portugal). Geomorphology, 94(3): 467495.

Zhang, L.L., Zhang, J., Zhang, L.M., and Tang, W.H. 2011. Stability analysis of rainfall-induced slope failure: a review. Proceedings of the ICE-Geotechnical Engineering, 164(5): 299.

Zhang, L., Li, J., Li, X., Zhang, J., and Zhu, H.,2016. Rainfall-Induced Soil Slope Failure Stability Analysis and Probabilistic Assessment. CRC Press Boca Raton. 


\section{Figure Captions}

Figure 1 Shallow landslide on line between Ljubljana-Kamnik, Slovenia (picture courtesy of Slovenian railways).

Figure 2 Graphical representation depicting the relationship between the probability of failure and the reliability index

Figure 3 Frequency and cumulative distribution of soil slope angles on Irish rail network

Figure 4 Finite element model mesh

Figure 5 Fragility curves for case study slope

Figure 6 Sensitivity analysis for a selection of input parameters: slope angle $(\alpha)$, internal angle of friction $(\varphi)$, the angle describing the rate of increase in shear strength due to matric suction $\left(\varphi^{b}\right)$, residual suction $\left(u_{a}-u_{w}\right)$, effective cohesion $\left(c^{\prime}\right)$ and their respective coefficients of variations (COVs)

Figure 7 Fragility curves for slope with $40^{\circ}, 45^{\circ}$ and $50^{\circ}$

Figure 8 Fragility curves for rainfall intensities of $3 \mathrm{~mm} / \mathrm{h}$ and $5 \mathrm{~mm} / \mathrm{h}$

Figure 9 Fragility curves for three different values of saturated permeability

Figure 10 Fragility curves for verification cases 


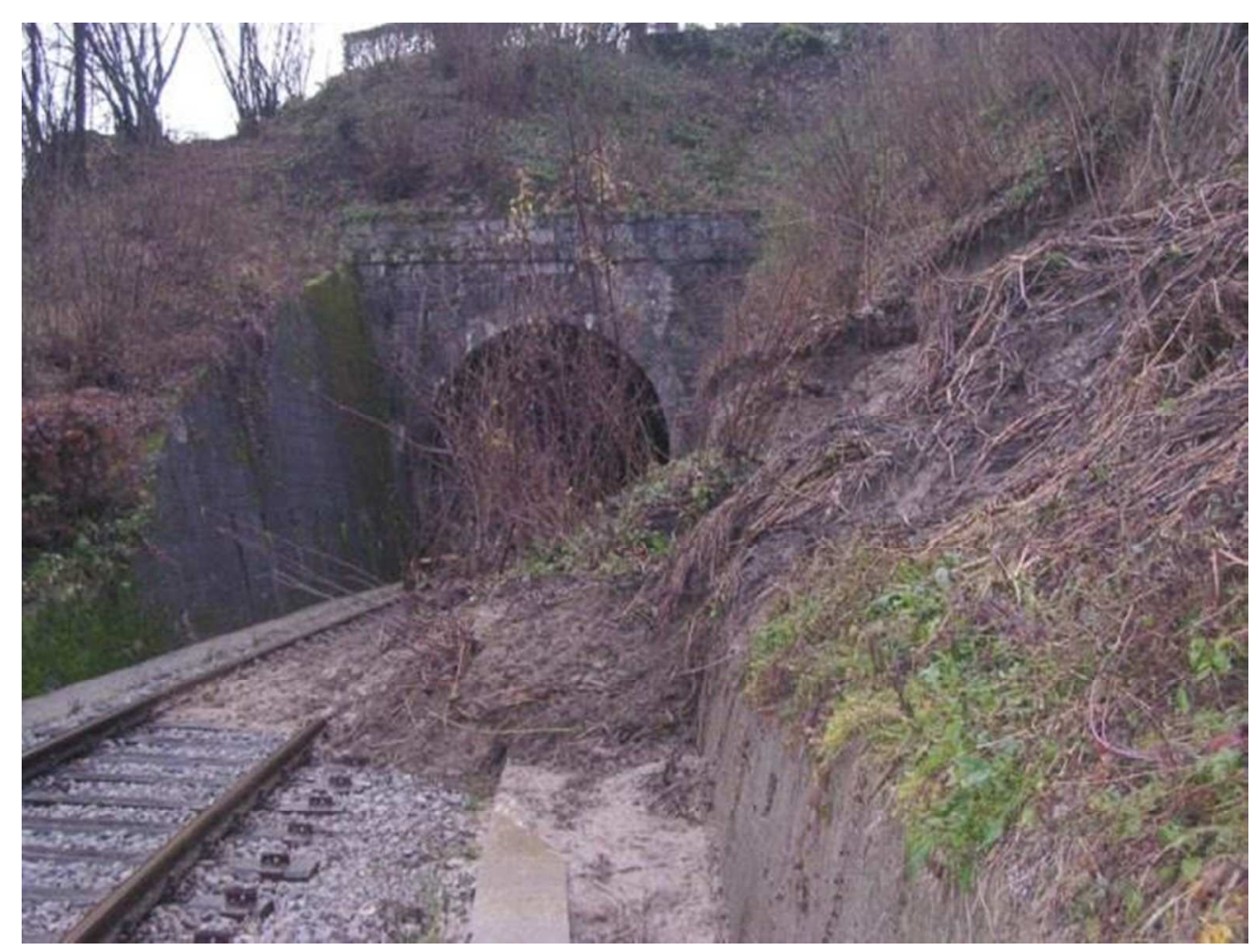

Figure 1 


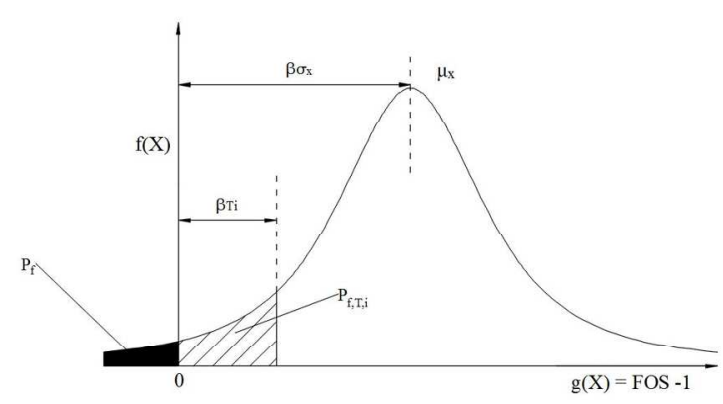

Figure 2

$502 \times 216 \mathrm{~mm}(96 \times 96 \mathrm{DPI})$ 


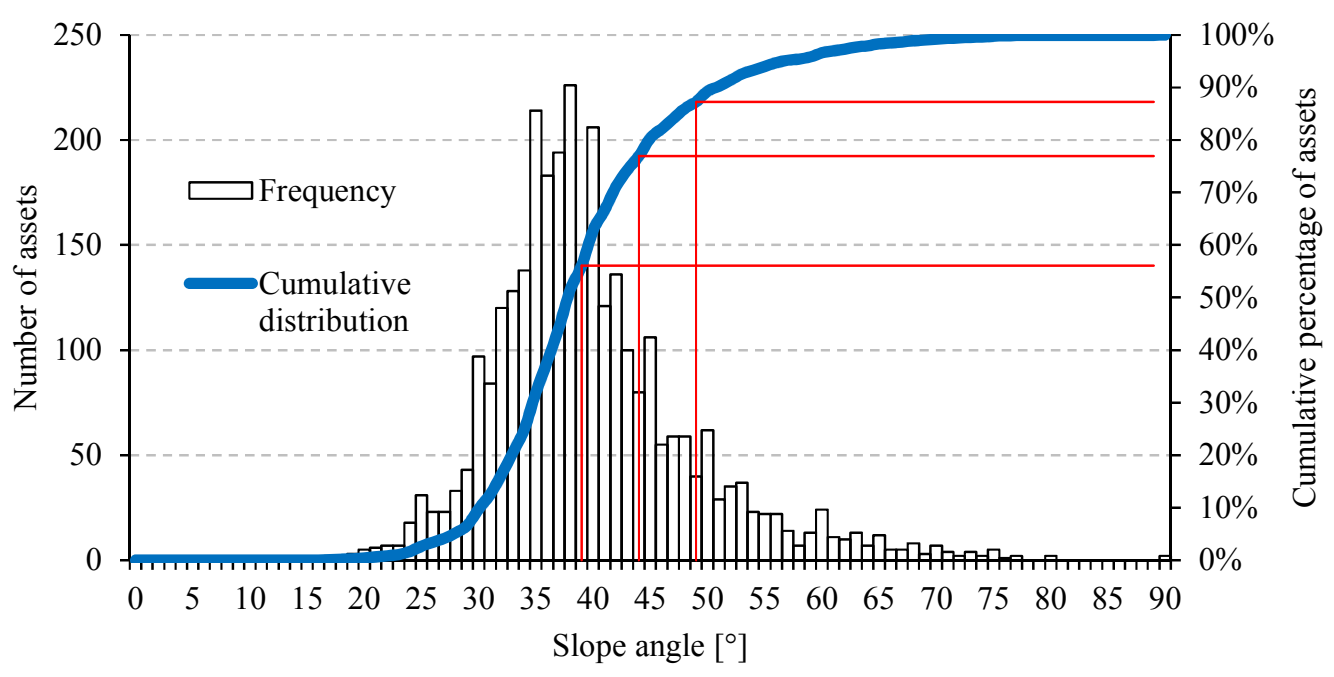




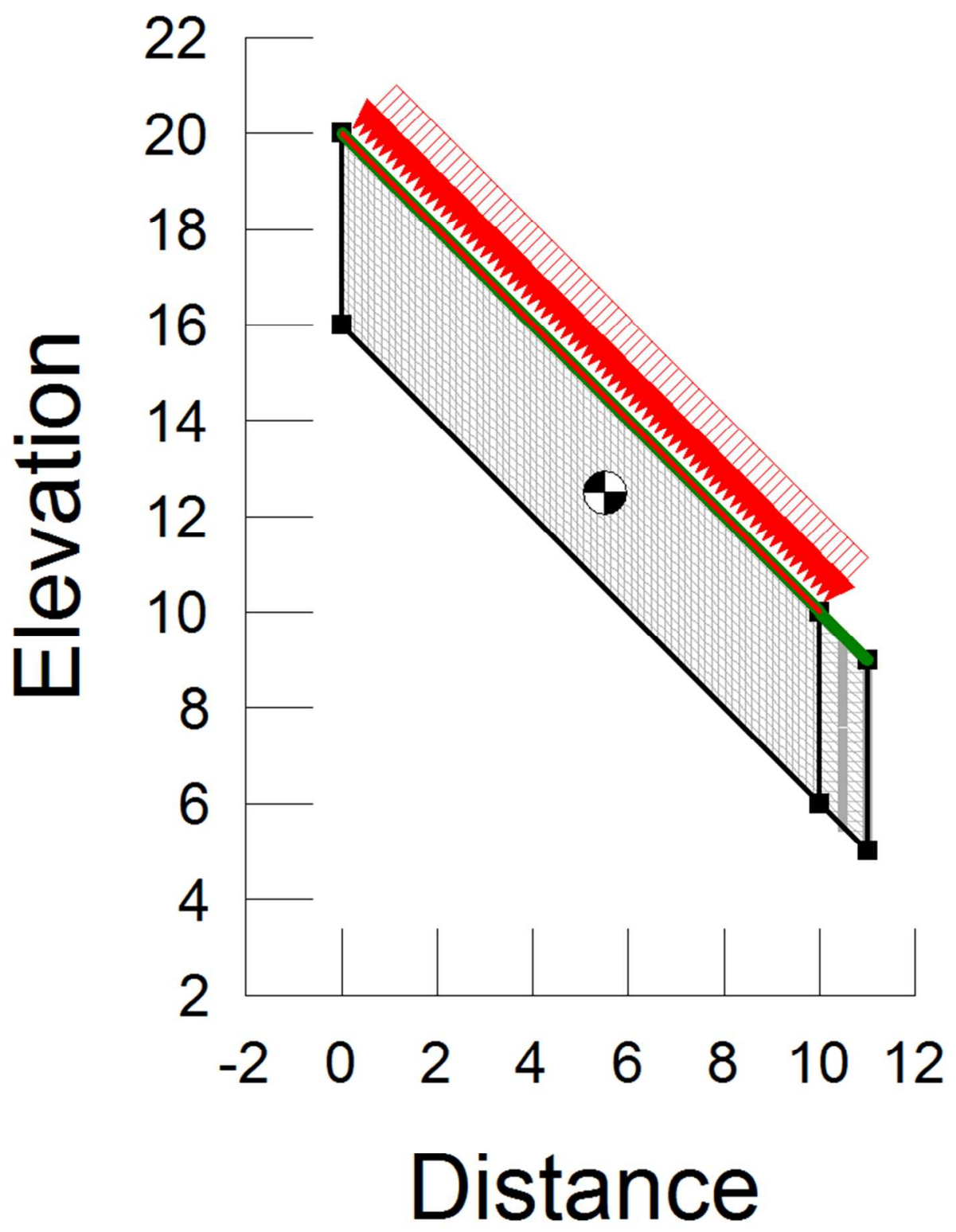

Figure 4

$221 \times 264 \mathrm{~mm}(96 \times 96 \mathrm{DPI})$ 


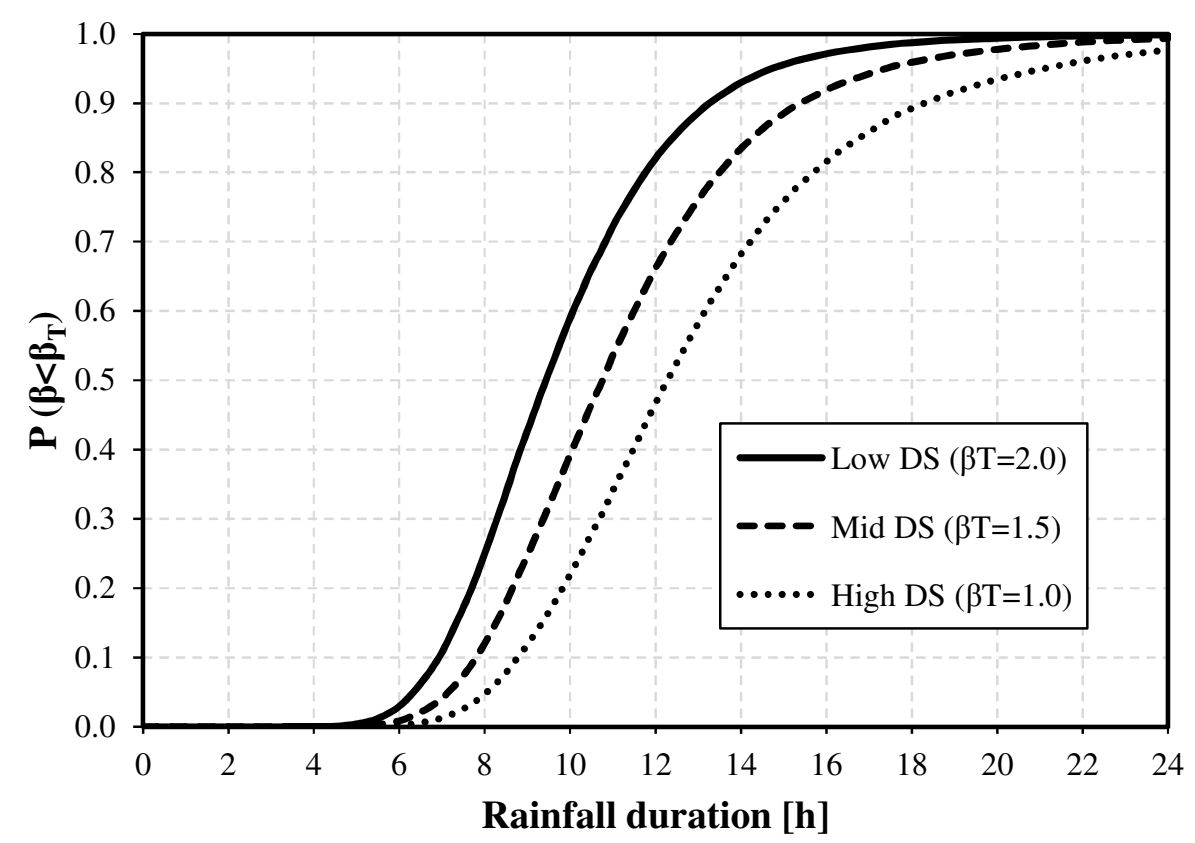

https://mc06.manuscriptcentral.com/cgj-pubs 


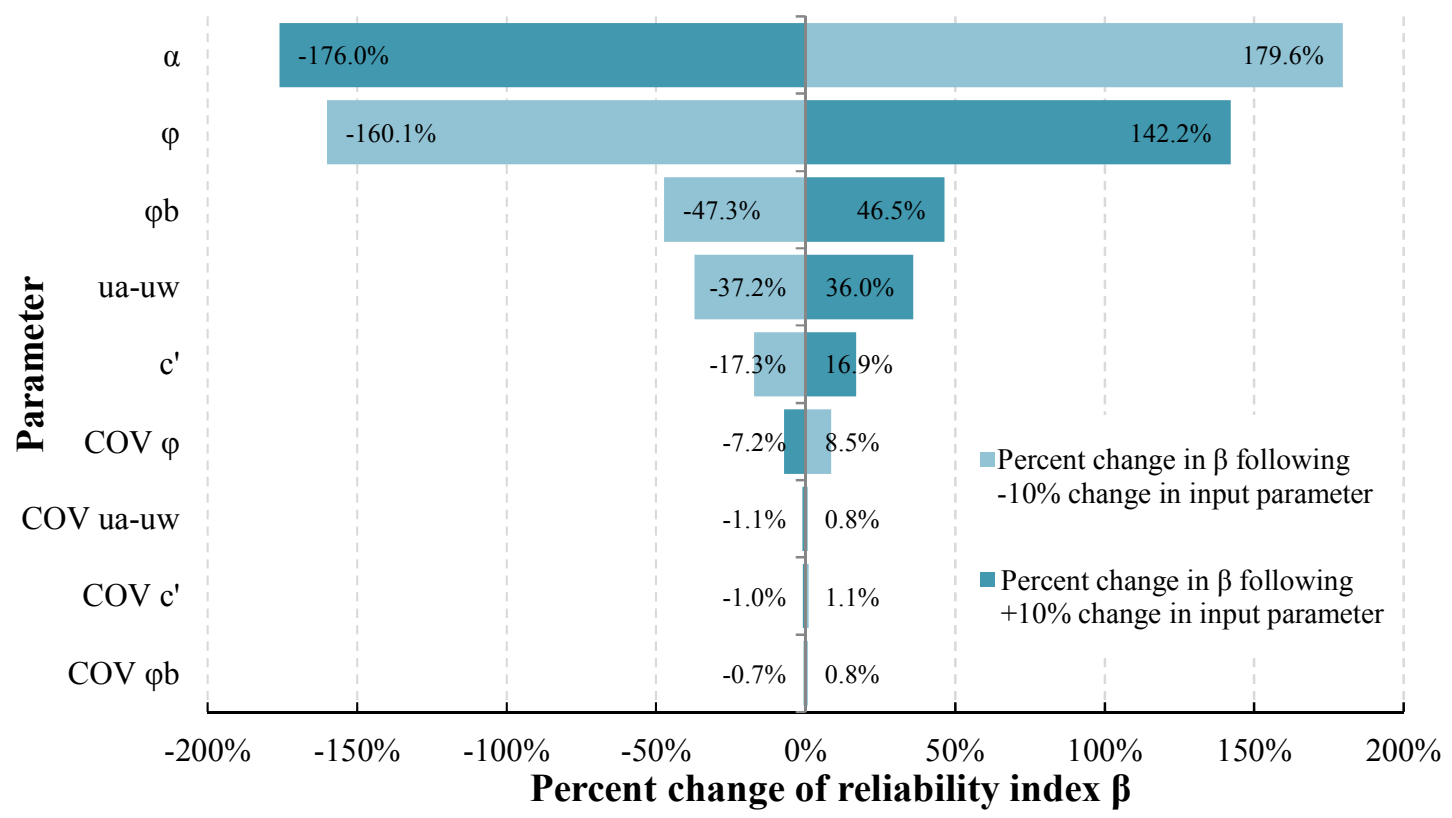




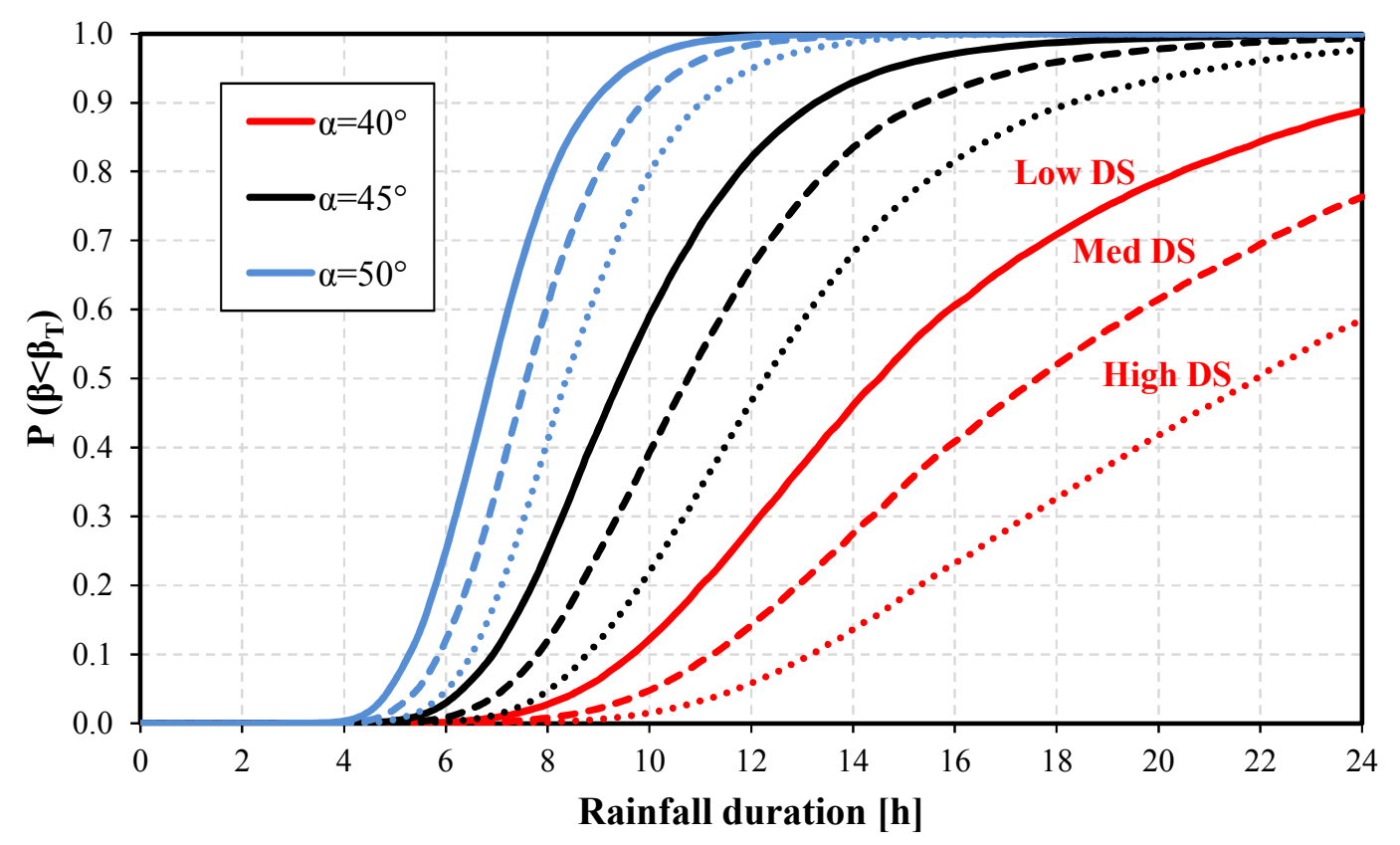




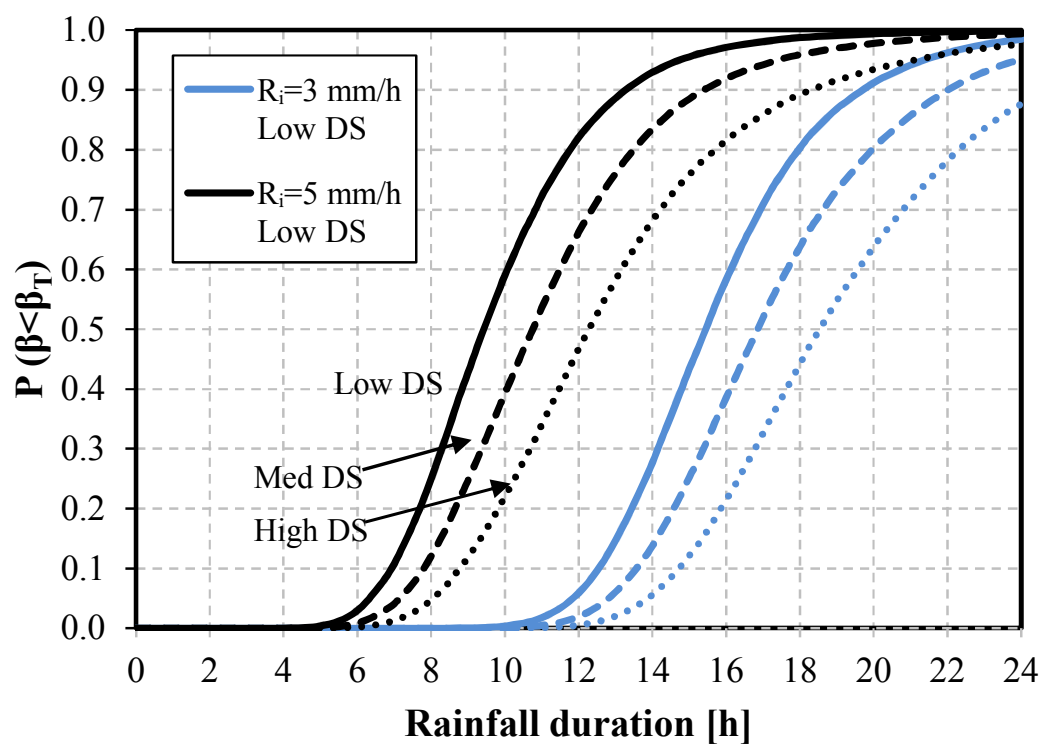

https://mc06.manuscriptcentral.com/cgj-pubs 


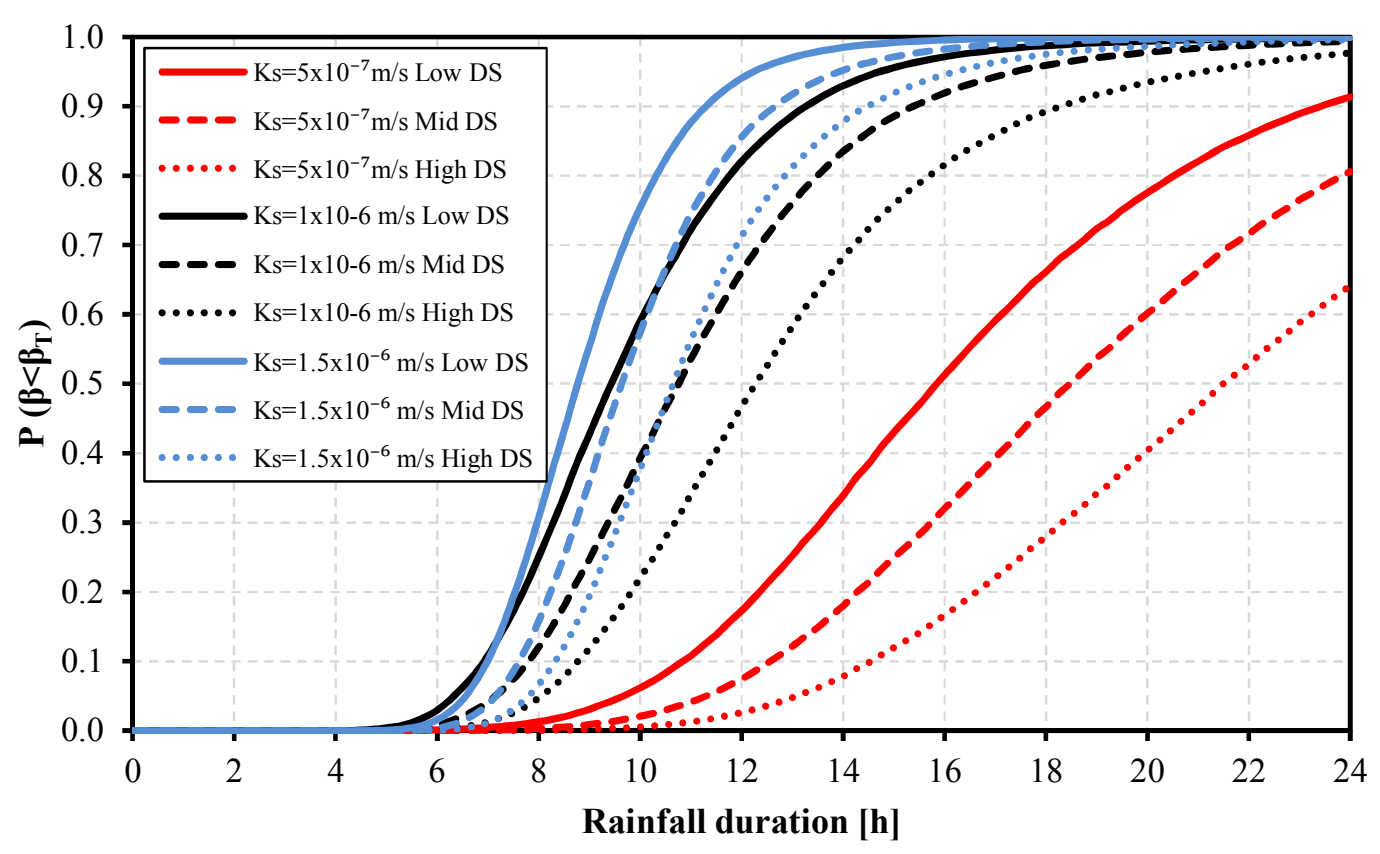




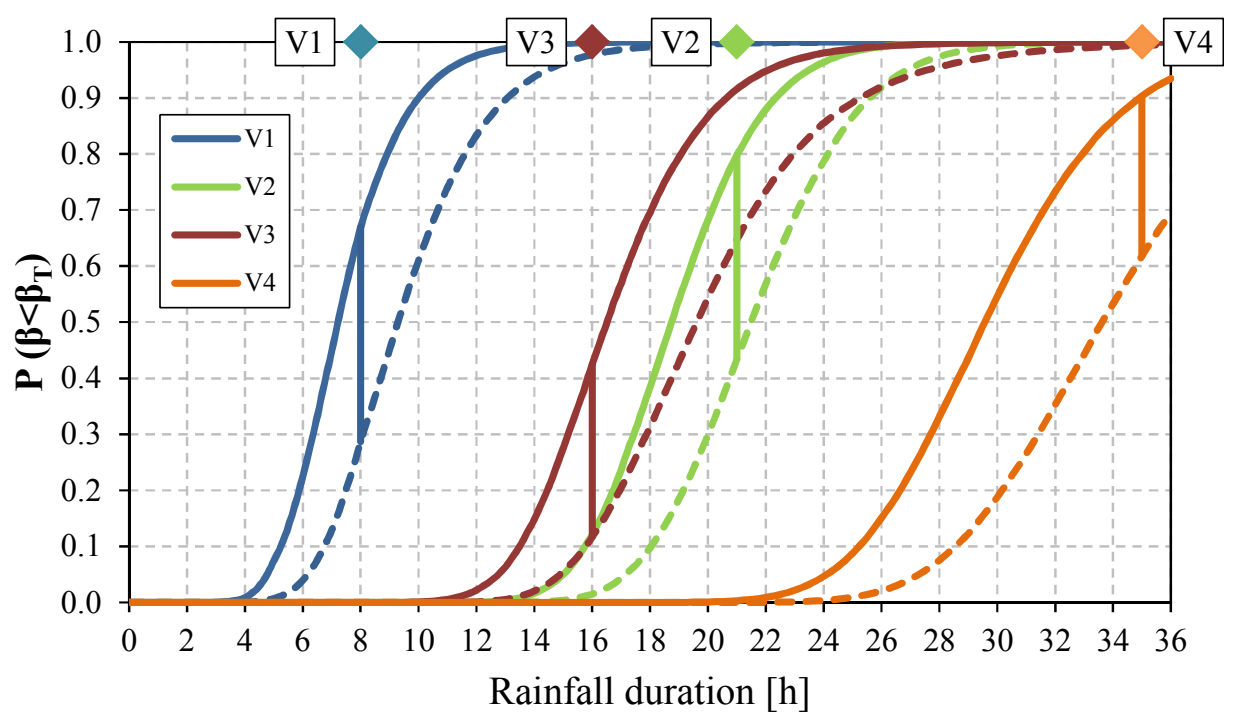

https://mc06.manuscriptcentral.com/cgj-pubs 
Table 1: Definition of damage states for fragility curves

\begin{tabular}{lll}
\hline Damage state & Performance level & $\beta_{\mathrm{T}}$ \\
\hline Low & Poor & 2.0 \\
Medium & Unsatisfactory & 1.5 \\
High & Hazardous & 1.0 \\
\hline
\end{tabular}

Table 2: Glacial till geotechnical parameters used in the case study slope

\begin{tabular}{|c|c|c|c|c|c|c|}
\hline & $\begin{array}{l}\text { Unit } \\
\text { weight } \\
\gamma\left[\mathrm{kN} / \mathrm{m}^{3}\right]\end{array}$ & $\begin{array}{l}\text { Angle of } \varphi^{\mathrm{b}}\left[{ }^{\circ}\right]^{*} \\
\text { internal } \\
\text { friction } \varphi^{\prime} \\
{\left[^{\circ}\right]}\end{array}$ & $\begin{array}{l}\text { Effective } \\
\text { cohesion c' } \\
{\left[\mathrm{kN} / \mathrm{m}^{2}\right]}\end{array}$ & $\begin{array}{l}\text { Saturated } \\
\text { permeability } \\
\mathrm{Ks}[\mathrm{m} / \mathrm{s}]\end{array}$ & $\begin{array}{l}\text { Initial } \\
\text { suction } \\
{\left[\mathrm{kN} / \mathrm{m}^{2}\right]}\end{array}$ & $\begin{array}{l}\text { Residual } \\
\text { suction } \\
{\left[\mathrm{kN} / \mathrm{m}^{2}\right]}\end{array}$ \\
\hline Mean value & 19 & 36 & 1 & $1 \times 10^{-6}$ & 20 & 3 \\
\hline $\mathrm{COV}$ & 0.02 & 0.1 & 0.2 & - & - & 0.1 \\
\hline
\end{tabular}

* angle indicating the rate of increase of the shear strength due to matric suction

Table 3: A summary of historical failures

\begin{tabular}{llccccc}
\hline No. & Location & Date & $\begin{array}{c}\text { Slope } \\
\left.\text { angle [ }{ }^{\circ}\right]\end{array}$ & $\begin{array}{c}\text { Rainfall } \\
\text { duration [h] }\end{array}$ & $\begin{array}{c}\text { Total } \\
\text { cumulative } \\
\text { rainfall [mm] }\end{array}$ & $\begin{array}{c}\text { Average } \\
\text { rainfall } \\
\text { intensity } \\
{[\mathrm{mm} / \mathrm{h}]}\end{array}$ \\
\hline V1 & Portarlington & $16 / 08 / 2008$ & 48 & 8 & 53.3 & 6.66 \\
V2 & Dublin (Cabra 1) & $14 / 11 / 2014$ & 52 & 21 & 41.5 & 1.98 \\
V3 & Wicklow & $30 / 12 / 2015$ & 45 & 16 & 43.5 & 2.72 \\
V4 & Dublin (Cabra 2) & $04 / 02 / 2009$ & 50 & 35 & 52.1 & 1.49 \\
\hline
\end{tabular}

